\title{
Over-the-scope-clip two-side closure of a coloduo- denal fistula caused by a dislocated prosthesis of the pancreatic duct
}

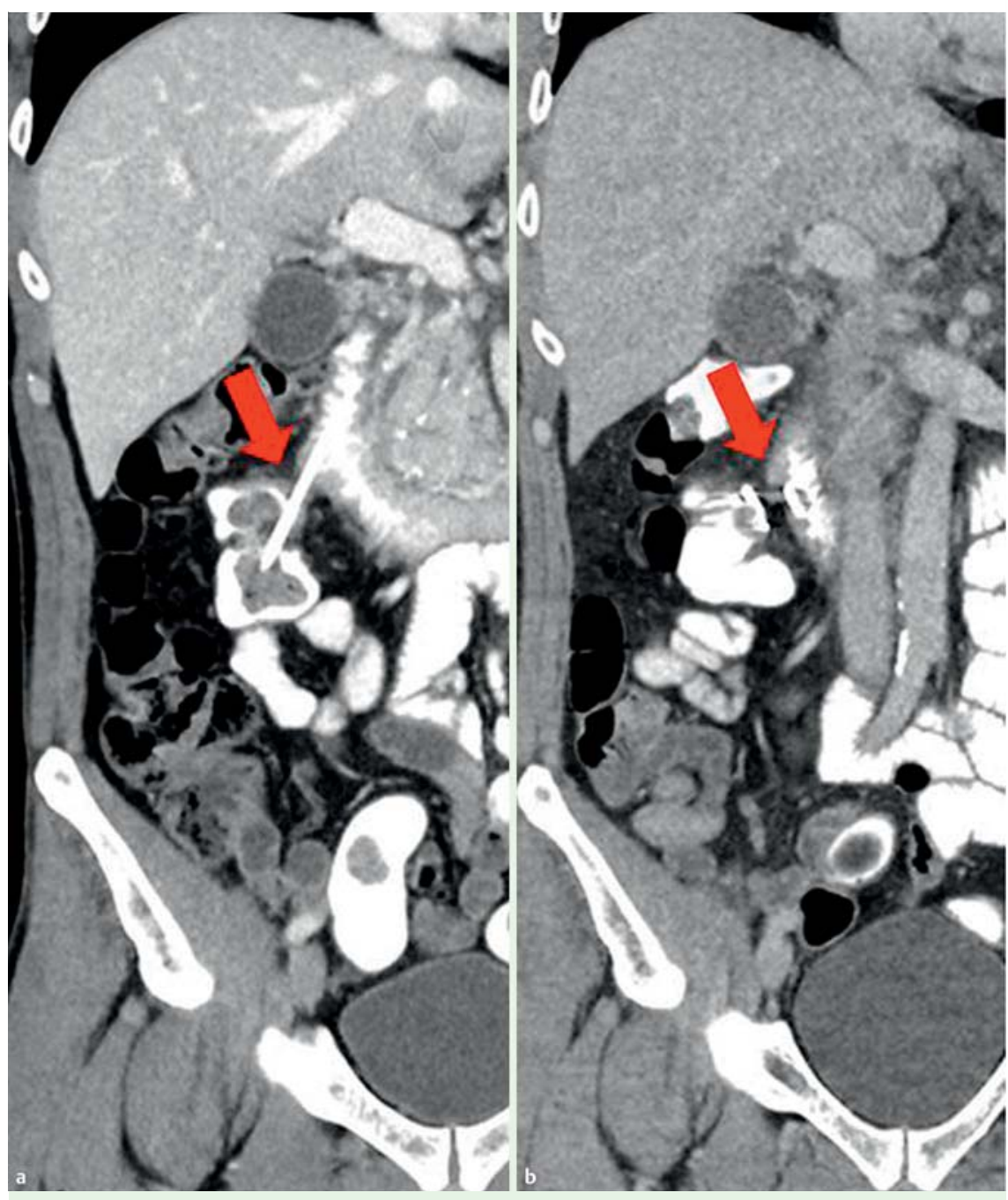

Fig. 1 a Coloduodenal fistula (arrow) in a patient with a dislocated pancreatic duct prosthesis, previously placed because of a disconnected duct syndrome due to necrotizing acute pancreatitis. b Fistula (arrow) after two-side closure with an over-the-scope clip.

The over-the-scope clip (OTSC; Ovesco Endoscopy, Tübingen, Germany) represents a technological advance in endoscopic devices and has made possible the treatment of emergency bleeding and the endoscopic closure of perforations, leaks, and fistulas of the upper and lower gastrointestinal tract $[1,2]$. However, available studies indicate that there are three factors with a statistically significant relationship to long-term success with this device: type of defect, primary versus rescue therapy, and chronicity of the defect. Furthermore, OTSC placement for fistula closure has had significantly lower long-term clinical success rates than placement for perforations and leaks [3]. To our knowledge, this is the first report of successful two-side closure of a coloduodenal fistula, caused by a dislocated pancreatic duct plastic prosthesis.

In June 2013, a patient underwent placement of a 7-Fr prosthesis (Mandel \& Rupp Medizintechnik, Erkrath, Germany), $6 \mathrm{~cm}$ in length, because of a disconnected duct syndrome due to necrotizing acute pancreatitis. This procedure was followed by a pancreaticojejunostomy in July 2013. In December 2014, the patient developed abdominal pain with an increase in in-
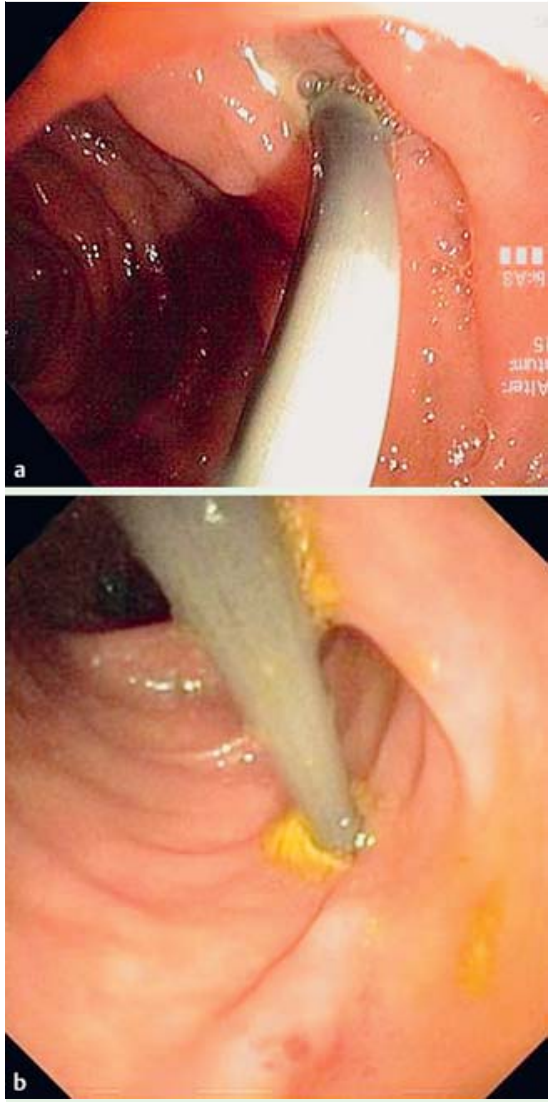

Fig. 2 a Penetration of the prosthesis through the wall of the duodenum. $\mathbf{b}$ Protrusion into the colon.

flammatory parameters: C-reactive protein $55 \mathrm{mg} / \mathrm{L}$, leukocytes $11,400 / \mu \mathrm{L}$, amylase $61 \mathrm{U} / \mathrm{L}$, lipase $223 \mathrm{U} / \mathrm{L}$. Assessments with computed tomography and endoscopy (gastroscopy, colonoscopy) showed a dislocated prosthesis penetrating the wall of the duodenum and colon ( $\bullet$ Fig. $1 \mathrm{a}$ and - Fig.2a,b), which indicated that removal of the prosthesis had simply been overlooked.

First, we marked the fistula orifice in the transverse colon with a through-thescope-clip to be able to identify it after removing the prosthesis ( $\bullet$ Fig. $\mathbf{2 b}$, - Fig.3b). In a second step, we removed the prosthesis transorally with a polypectomy snare and closed the fistula of the duodenum with an $11 \mathrm{t}$ OTSC ( $\bullet$ Fig.3a). In a last step, we closed the fistula of the colon with a 14t OTSC ( $\bullet$ Fig.3b). The suction-and-anchor method was used. To 


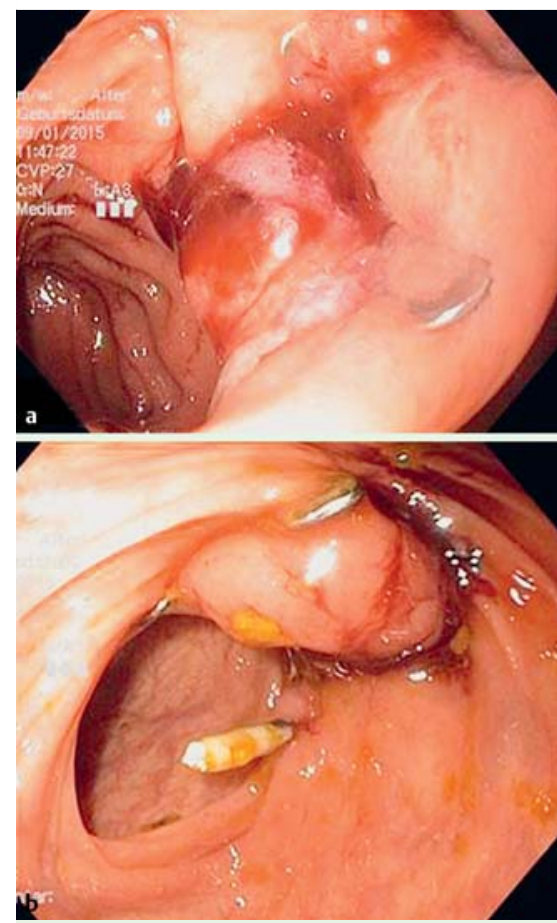

Fig. 3 Fistula closure on both sides: duodenum (a) and colon (b). The fistula orifice was marked with a through-the-scope clip before removal of the prosthesis (b).

prevent the risk of an air embolism, carbon dioxide insufflation was used.

After the procedure, the patient reported being symptom free. The corresponding clips in the duodenum and colon are shown in Fig. 1 b. The clips were still in place after a follow-up period of 80 days, and the patient was still free of symptoms. The acute occurrence of pain, the constellation of inflammatory signs, and the endoscopic findings, including presence of the prosthesis and absence of signs of tissue fibrosis, indicated that the fistula was of recent origin.

In conclusion, two-side OTSC placement can be a safe and effective procedure in patients with enteroenteric fistulas. In our opinion, the following condition must be met before this alternative is used: the fistula must be of recent development, which means that the fistula is not yet established. This is necessary to prevent the perforation of a hollow organ after extraction of the foreign body.

\section{Endoscopy_UCTN_Code_CPL_1AK_2AG}

\section{Competing interests: None}

\section{Hans-Juergen Richter-Schrag, Andreas Fischer}

Interdisciplinary Endoscopy, Department of Medicine II and Department of General and Visceral Surgery, University of Freiburg, Freiburg, Germany

\section{References}

1 Kirschniak A, Subotova N, Zieker D et al. The over-the-scope clip (OTSC) for the treatment of gastrointestinal bleeding, perforations, and fistulas. Surg Endosc 2011; 25: $2901-2905$

2 Meningen $R$, Senninger $N$, Laukoetter MG. Novel treatment options for perforations of the upper gastrointestinal tract: endoscopic vacuum therapy and over-the-scope-clip. World J Gastroenterol 2014; 20: 7767 - 7776

3 Haito-Chavez Y, Law JK, Kratt T et al. International multicenter experience with an over-the scope clipping device for endoscopic management of GI defects. Gastrointest Endosc 2014; 80: 610-622

\section{Bibliography}

DOI http://dx.doi.org/

10.1055/s-0034-1392089

Endoscopy 2015; 47: E301-E302

(c) Georg Thieme Verlag KG

Stuttgart · New York

ISSN 0013-726X

\section{Corresponding author}

\section{Hans-Juergen Richter-Schrag, MD}

Interdisciplinary Endoscopy

Department of Medicine II and

Department of General and Visceral Surgery

University of Freiburg

Sir-A-Krebs Street

Freiburg D-79106

Germany

Fax: +49-761-270-27750

hans-juergen.schrag@uniklinik-freiburg.de 